\title{
Axillary hyperhidrosis treatment by simple skin excision and undermining
}

\author{
Charles Kettle MD FRCSC, Arnis Freiberg MD FRCSC FACS \\ Division of Plastic Surgery, The Toronto Hospital, Western Division, Toronto, Ontario
}

\section{Kettle, A Freiberg. Axillary hyperhidrosis treatment by simple skin excision and undermining. Can J Plast Surg 1999;7(6):267-272.}

\begin{abstract}
The current literature of axillary hyperhidrosis is reviewed. Excision of the gland-containing skin of the axilla has been a mainstay in the treatment of axillary hyperhidrosis for many years. A retrospective study was performed using data accumulated from 56 consecutive patients who underwent a surgical procedure modified from that originally described by Hurley and Shelley. Excision of the hair-bearing portion of the axilla with undermining of the adjacent skin and simple closure was performed under local or general anesthesia. Ninety-two per cent of patients were satisfied with the results. Five patients wished to undergo a second procedure, either because they still had excessive perspiration or because they were unhappy with their scars. Complication rates were low and were compared with other series. Thus, the described procedure provides a simple, safe and effective modality for the treatment of axillary hyperhidrosis.
\end{abstract}

Key Words: Axilla; Hyperhidrosis; Surgery; Sweat glands

\section{Traitement de l'hyperhidrose axillaire par simple excision de la peau et décollement}

RÉSUMÉ : La littérature courante sur l'hyperhidrose axillaire est passée revue. L'excision de la peau de l'aisselle contenant les glandes a constitué le pivot du traitement de l'hyperhidrose axillaire pendant de nombreuses années. Une étude rétrospective a été réalisée en utilisant des données recueillies sur 56 patients consécutifs qui ont subi une intervention chirurgicale modifiée par rapport à celle décrite à l'origine par Hurley et Shelley. L'excision de la portion soutenant les poils de l'aisselle avec un décollement de la peau adjacente et une fermeture simple a été réalisée sous anesthésie locale ou générale. Quatre-vingt-douze pour cent des patients étaient satisfaits des résultats. Cinq patients souhaitaient subir une deuxième intervention, soit parce qu'ils souffraient toujours de sudation excessive ou parce qu'ils n'étaient pas satisfaits des cicatrices. Les taux de complication étaient faibles et ont été comparés à d'autres séries. Ainsi, la technique décrite offre une modalité simple, sûre et efficace pour le traitement de l'hyperhidrose axillaire.

A xillary hyperhidrosis is a condition characterized by an excessive, usually unprovoked, production of sweat. In its idiopathic form it affects $0.6 \%$ to $1.0 \%$ of the population (1), and may be confined to the axilla or involve the palms and soles. It also occurs secondarily as a feature of other systemic diseases (ie, thyrotoxicosis, hypoglycemia). Sweating occurs in bursts, usually associated with emotional situations, but may be spontaneous (2). When present, axillary hyperhidrosis can be the cause of tremendous embarrassment to the patient and, when severe, may even cause clothes to rot $(3,4)$. It is more common in women, usually presenting in the late teens or early 20 s. There appears to be an increased inci-

\footnotetext{
Correspondence and reprints: Dr Arnis Freiberg, The Toronto Hospital, Western Division, 399 Bathurst Street, Edith Cavell Wing 4-034.

Toronto, Ontario M5T 2S8. Telephone 416-603-5691, fax

416-603-5297e-mail afreiberg@torhosp.toronto.on.ca
}

dence among family members, implicating a genetic predisposition. Axillary hyperhidrosis is more common in individuals suffering from hyperhidrosis of the palms of the hands and/or soles of the feet. There does not appear to be an increase in the incidence of bromidrosis associated with axillary hyperhidrosis (5). Most patients present for medical or surgical treatment. This paper reviews current practices and demonstrates an effective, simple surgical procedure for the treatment of axillary hyperhidrosis.

\section{PATIENTS AND METHODS}

During the 13 year study period, 57 consecutive patients aged 17 to 48 underwent excision of the axillary sweat glands. The patients were referred by family physicians, dermatologists or other patients. Patients in this study were assessed as requiring surgery for relief of symptoms after conservative management had proved unsuccessful. Initial preoperative as- 


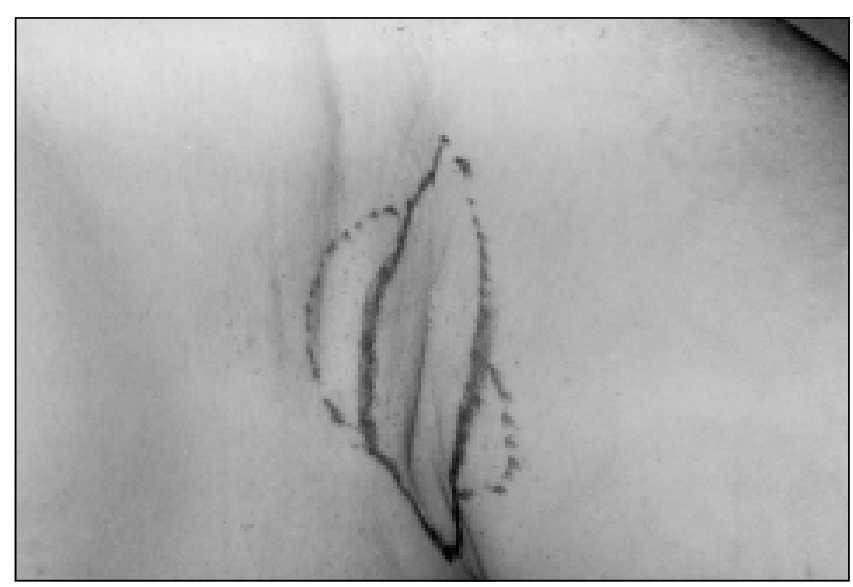

Figure 1) Preoperative marking for skin excision and undermining for the treatment of axillary hyperhidrosis

TABLE 1

Age range of patients treated surgically for axillary hyperhidrosis

\begin{tabular}{lccc}
\hline Age (years) & Male & Female & Total \\
\hline$<15$ & 0 & 0 & 0 \\
$16-20$ & 0 & 4 & 4 \\
$21-25$ & 4 & 11 & 15 \\
$26-30$ & 6 & 12 & 18 \\
$31-35$ & 3 & 9 & 12 \\
$36-40$ & 2 & 2 & 4 \\
$41-45$ & 0 & 1 & 1 \\
$46-50$ & 0 & 2 & 2 \\
$>50$ & 0 & 0 & 0 \\
\end{tabular}

sessment included use of the iodine-starch test, as described by Weaver (6), to identify the hyperhidrotic area present in the axilla. After observing that the hyperhidrotic area corresponded with the hair-bearing area in all cases, the iodinestarch test was abandoned, and the hair-bearing area was excised. Other investigators have reported similar findings $(2,7,8)$.

Surgery was usually performed under local and sometimes general anesthesia in a day surgery setting. No perioperative antibiotics were administered, because these have not been shown to reduce wound infection rates following surgery (9). A transverse elliptical incision was made between the anterior and posterior axillary folds. An ellipse of skin ranging from $3 \times 1 \mathrm{~cm}$ to $10 \times 3 \mathrm{~cm}$ was excised, depending on the size of the hair-bearing area. Undermining of the axillary skin deep to the dermis followed, extending 2 to $3 \mathrm{~cm}$ from the excision site and additional subcutaneous glandular tissue was removed (Figure 1). The axillary skin was closed in two layers, and a pressure dressing was fitted to fill the axillary dome. Patients returned three to five days later for postoperative assessment and dressing change. Daily showers were suggested, and patients returned seven to 10 days after surgery for suture removal. Short term follow-up was carried
TABLE 2

Area of axillary skin excised for the treatment of axillary hyperhidrosis

\begin{tabular}{lccc}
\hline Area excised $\left(\mathbf{c m}^{2}\right)$ & Male & Female & Total \\
\hline $0.0-4.0$ & 2 & 5 & 7 \\
$4.1-8.0$ & 7 & 18 & 25 \\
$8.1-12.0$ & 6 & 13 & 19 \\
$12.1-16.0$ & 2 & 4 & 6 \\
$16.1-20.0$ & 0 & 2 & 2 \\
$20.1-24.0$ & 0 & 1 & 1 \\
Total & 17 & 43 & 55 \\
\hline
\end{tabular}

out at six and 12 weeks postoperatively. Long term follow-up consisted of a questionnaire completed by patients between three and 10 years postoperatively.

\section{RESULTS}

There were 57 patients in the study. One patient was lost to follow-up and was excluded from the study. One hundred and twenty-four axillary surgical procedures were completed in total (all procedures were bilateral; five patients underwent a repeat procedure). Results of 122 procedures were available for follow-up. Given the nature of the disease and patient selection criteria, there was no control group.

The average age was 28.5 years for women and 28.9 years for men. The male to female ratio was 1:2.7 (Table 1), which is similar to that reported by others (9). The area of axillary skin excised ranged from $3 \times 1 \mathrm{~cm}$ to $10 \times 3 \mathrm{~cm}$. The mean area excised was $8.9 \mathrm{~cm}^{2}$ in men and $9.4 \mathrm{~cm}^{2}$ in women (Table 2).

\section{Complications}

There were no major complications, large hematomas or skin slough (Table 3). Six axillae (4.9\%) developed hematomas, five of which required drainage under local anesthesia. One axilla $(0.8 \%)$ developed a small seroma that did not require drainage. Four axillae $(3.3 \%)$ developed postoperative wound infection. All were treated with oral antibiotics and did not require hospitalization. One axilla $(0.8 \%)$ developed an abscess that required incision and drainage under local anesthesia. Skin edge necrosis occurred in two axillae (1.6\%). Healing was allowed to occur by secondary intention and both patients stated having satisfactory results three months after surgery. Hypertrophic scarring occured in two axillae $(1.6 \%)$. One patient had the scar injected with a steroid and considered the result satisfactory seven months postoperatively. Although some patients experienced discomfort on abduction of the arms at six weeks, no restriction in arm movements was observed three months following surgery.

Functional and cosmetic results were assessed subjectively by the patient at each postoperative visit and recorded in the chart as either satisfactory or unsatisfactory. Fifty of the 57 patients $(88 \%)$ were satisfied with the result at the end of short term follow-up (three months). All patients who experienced a minor complication were satisfied with the result once the complication had been treated. Two patients (3.5\%) who did not experience any postoperative complication felt 
that their perspiration level remained excessive and did not return for further treatments. Five patients $(8.8 \%)$, one of whom experienced a complication, felt that their functional result was unsatisfactory. They again underwent excision, and all were satisfied with their final result.

Long term results (Table 4 ) were assessed by means of a questionnaire mailed to patients two to 10 years following the original surgery. Results from 12 patients (21\%) were obtained. Questionnaires mailed with postage-paid return envelopes to the remaining patients either were not returned because of lack of interest in participating or did not reach the patients because of a change of address. Nine of the 12 patients $(75 \%)$ felt completely satisfied with the results of the operation.

Two patients $(17 \%)$ felt that there was subjective improvement of their symptoms but were not completely satisfied with the result, and one patient (8\%) felt that there was no change. All patients felt that the scars were acceptable or good. There were no reports of limitation of movement of the arm. Five patients $(42 \%)$ felt that the immediate postoperative period was uncomfortable or painful but stated that they would have the same procedure repeated if they suffered from similar symptoms. One of 12 patients (8\%) reported a prolonged decrease in the sensitivity in the axilla. Eleven of 12 patients $(92 \%)$ stated that they would have the procedure repeated and would recommend the procedure to others.

\section{DISCUSSION}

There are two types of sweat glands present in the human skin (10). Eccrine glands are present over the entire surface of the body and are innervated by cholinergic fibres of the sympathetic nervous system (11). Apocrine glands are found
TABLE 3

Complications following surgical treatment of axillary hyperhidrosis

\begin{tabular}{lcc}
\hline Complications & $\begin{array}{c}\text { Number of wounds } \\
(\mathbf{n}=\mathbf{1 1 0})\end{array}$ & Percentage \\
\hline Seroma & 1 & 0.9 \\
Hematoma & 6 & 5.5 \\
Infection & 4 & 3.6 \\
Abscess & 1 & 0.9 \\
Skin necrosis & 2 & 1.8 \\
Hypertrophic scar & 2 & 1.8 \\
\hline
\end{tabular}

in the skin of the external auditory meatus, nipple, areola, axilla and anogenital region. The axilla contains both types of glands, in an approximate 1:1 ratio (11). Eighty per cent of the glands are found in a small area of the dome of the axilla in the hair-bearing area (5). Hyperhidrosis is thought to occur in the presence of histologically normal glands and nerves, although these may be present in greater than normal numbers and may be functionally hyperactive (12).

At present, most investigators attempt initial treatment using aluminum chloride hexahydrate $20 \%$ to $25 \%$ solution in ethanol or other topical agents such as glutaraldehyde, tannic acid, local anesthetics or formaldehyde. These agents are effective in some cases $(13,14)$ but require prolonged courses of treatment to be of any benefit. Solutions must be applied for 6 to 8 hours at a time after meticulous cleansing and drying of the axilla, up to three to four times per week. Local reactions are seen frequently and are reported to occur in $1.5 \%$ to $55 \%$ of cases (15).

Anticholinergic medications are also used in the treatment

TABLE 4

Long term follow-up questionnaire two to 10 years following surgical treatment of axillary hyperhidrosis

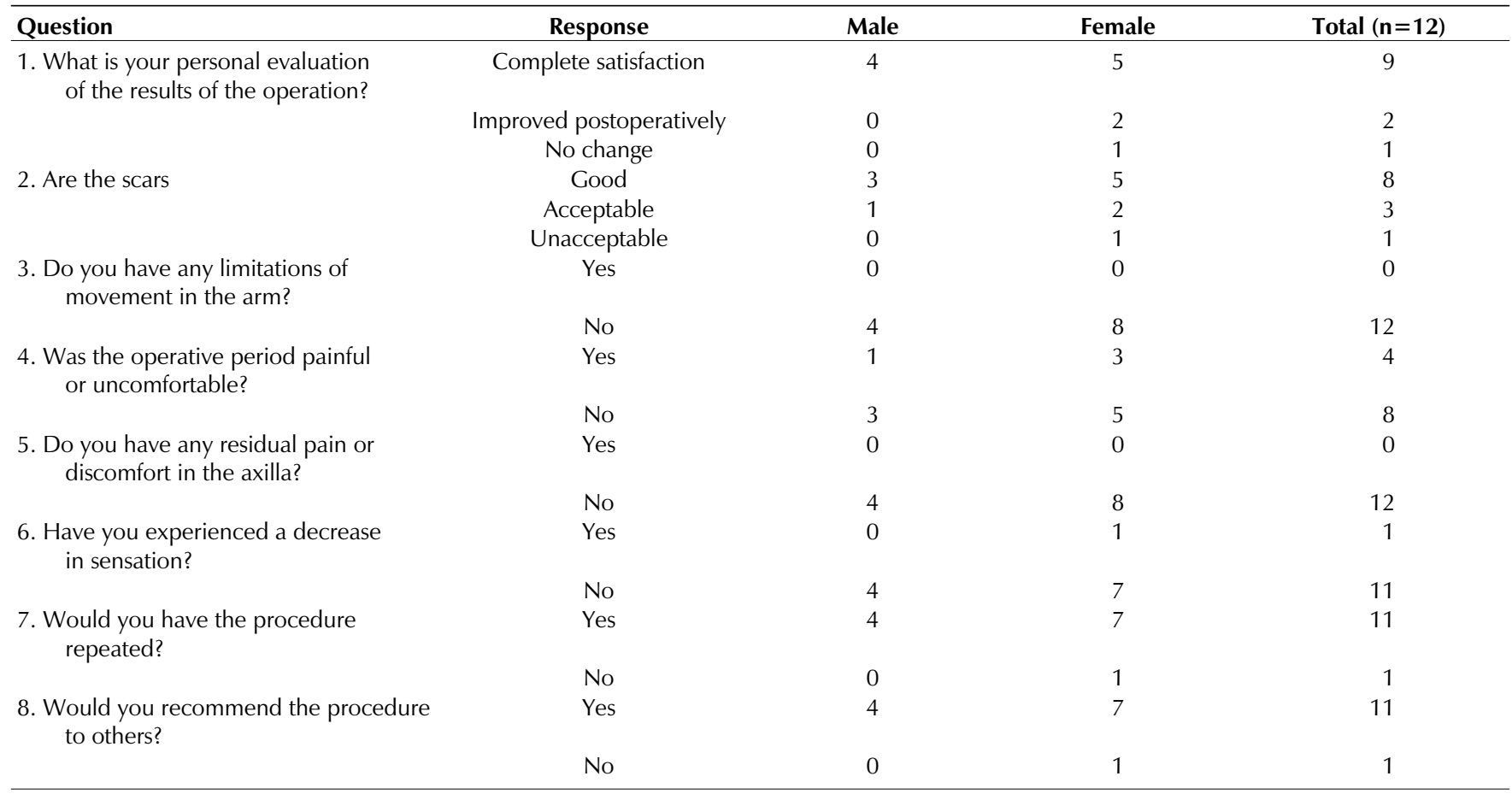




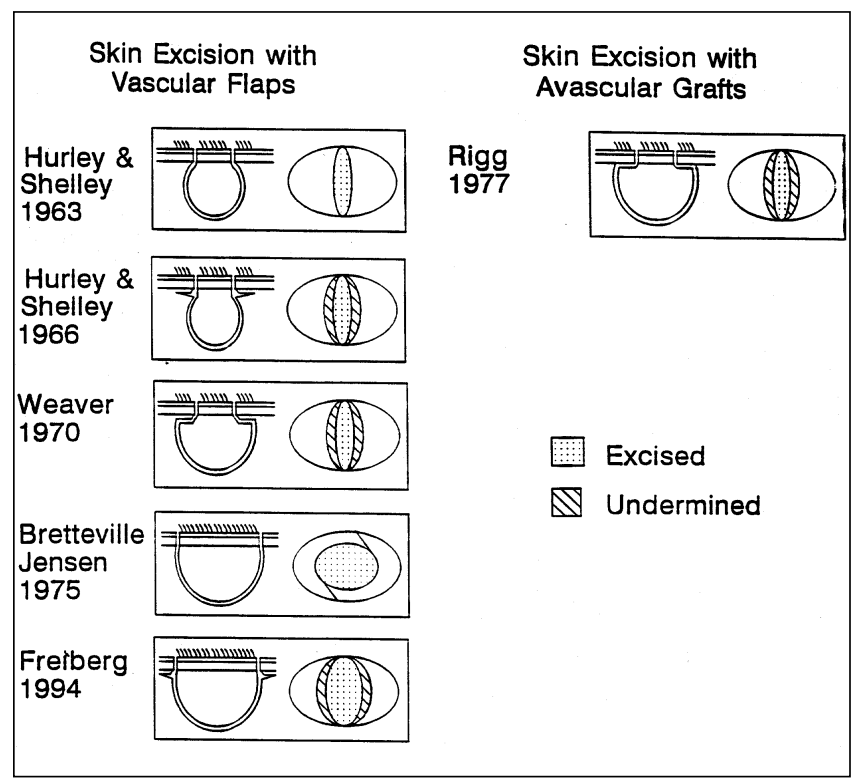

Figure 2) Surgical techniques using skin excision for treatment of axillary hyperhidrosis

of axillary hyperhidrosis but benefits are transient (15) and unpleasant anticholinergic side effects may occur. Glycopyrrolate is most often used and may be combined with phenobarbital to treat patients with an emotional aspect of the hyperhidrosis.

Iontophoresis has also been used. The application of constant voltage and current across tap water or anticholinergic compounds (poldine methosulphate or glycopyrronium bromide) applied to the palms and soles has proved effective in some cases $(16,17)$. However, the treatment of axillary hyperhidrosis using special electrodes has proved less effective (17).

Other investigators have attempted to treat axillary hyperhidrosis using electrosurgery with insulated needles (18). They feel that, although the degree of sweat inhibition is much less than with other procedures, the paucity of side effects make this a viable form of therapy (18).

Local radiation has been used but can result in irreversible damage to the axillary skin. This technique has largely been abandoned for more effective treatments with less morbidity.

Sympathectomy as a means of treating hyperhidrosis has proved effective in cases involving the palms but has been less successful in reducing axillary eccrine gland activity. Several approaches exist to facilitate resection of the sympathetic chain $(19,20)$. Resection of the second thoracic ganglion alone has been shown to be effective in reducing sweating in palmar hyperhidrosis, but in order to effectively reduce sympathetic innervation to the axilla, it is necessary to resect the second, third and occasionally the fourth and fifth ganglia (20). These procedures are much more involved and require general anesthesia and a two to three day hospital stay. The usual postoperative complications exist as well as pneumothorax and Horner's syndrome. Compensatory hyperhidrosis is reported in $18 \%$ to $44 \%$ of cases $(19,20)$. Because palmar hyperhidrosis is effectively treated in greater

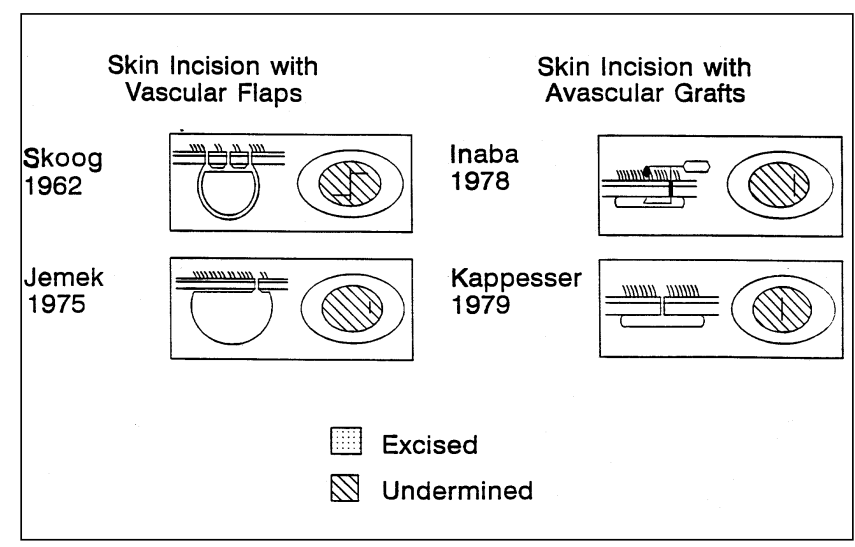

Figure 3) Surgical techniques using skin excision for treatment of axillary hyperhidrosis

than $95 \%$ of cases and the result is permanent, sympathectomy is probably best reserved for the treatment of severe palmar hyperhidrosis or hyperhidrosis existing with peripheral vascular disease in the upper extremities. With the trend to minimal access surgery, transaxillary sympathectomy is now being performed endoscopically. Initial reports reveal results as good as with the conventional open technique but with reduced morbidity.

Recently, several investigators have reported the use of suction assisted lipolysis in the treatment of axillary hyperhidrosis $(21,22)$. Although the number of patients treated in this fashion has been limited, the authors claim promising results over a short period of follow-up with low morbidity. Further evaluation is necessary before advocating this technique in the treatment of axillary hyperhidrosis.

Cryosurgery has been advocated by some investigators in the treatment of axillary hyperhidrosis. Cyroprobe tips ranging form $13 \times 9 \mathrm{~mm}$ to $13 \times 18 \mathrm{~mm}$ in diameter are held against the axillary skin for 2 mins in multiple areas after infiltration with local anesthetic. Limited trials with short follow-up have demonstrated some success. However, up to $50 \%$ of patients continue to have excessive axillary sweating. Full thickness skin loss occurs in up to $25 \%$ of patients. Late sequelae include depigmentation and depilation (23).

Procedures for the surgical treatment of axillary hyperhidrosis may be divided into those that excise axillary skin and those that incise the skin to gain access to underlying glands. These procedures may be further divided according to whether vascular skin flaps or avascular grafts are used for closure.

Since the description of the first surgical procedure for treating axillary hyperhidrosis by Skoog in 1962 (24), numerous surgical procedures have been developed (Figure $2,3)$. Surgery for hyperhidrosis results in a reduction in the number of sweat glands present in the axilla. Ideally, all active glands should be removed from the subcutaneous tissues and deep dermis. If skin is not excised with the glands, the subdermal vascular plexus may be scraped under the flaps at the time of surgery and may result in reduced glandular activity. This effect is temporary because gland function increases with reinnervation. 
Skoog and Thyresson's (24) original procedure involved creating four vascularized flaps of axillary skin via an offset cruciate incision. The subdermal vascular plexus was left intact. The deeper sweat glands were excised, but numerous more superficial glands remained in the axilla. Although patients experienced a significant reduction in sweating, they continued to have episodes of embarrassing sweating when under emotional stress. Jemec and Hansen (25) performed subcutaneous gland curettage through a single incision leaving vascularized skin flaps. Kappesser (26) created a single incision transversely in the axillary skin and used a housed razor blade to trim the undersurface of the dermis, including the subdermal plexus. He essentially created avascular flaps (grafts). Yoshikata et al (8) advocated a similar technique where one or two parallel incisions are made, the skin reflected back and the undersurface trimmed using scissors, also excising the subdermal plexus and lower third of the dermis.

Hurley and Shelly (27) described the excision of a transverse ellipse of axillary skin with subcutaneous glands in 1963. Later they added the undermining of adjacent axillary skin, presumably because patients continued to experience excessive perspiration (5). Attention was focused on the dome of the axilla, which contains $70 \%$ to $80 \%$ of glands in the axilla. Numerous other investigators described similar procedures. Weaver (6) subsequently described the elliptical excision and subcutaneous clearance of glands from undermined vascular skin flaps. In this fashion, sweat glands were removed from adjacent tissues and denervated; however, superficial glands remained within the vascular flaps. Rigg (3) advocated use of a similar elliptical skin excision, but to remove the superficial glands, he created avascular flaps (grafts) that facilitated closure. Bretteville-Jensen et al (28) excised a larger ellipse of axillary skin containing the entire hairbearing portion of the axilla with subcutaneous clearance of glands. A Z-plasty was used during skin closure. Eldh and Fogdestam (29) performed a similar procedure but closed the skin in an $\mathrm{M}$ or $\mathrm{V}$ shape.

In this paper a method of glandular excision similar to

\section{REFERENCES}

1. Adar R, Kurchin A, Zweig A, Mozes M. Palmar hyperhidrosis and its surgical treatment: a report of 100 cases. Ann Surg 1977;186:34-41.

2. Jepson RP, Harris JD. Surgical aspects of hyperhidrosis. Australas J Dermatol 1976;17:90-1.

3. Rigg B. Axillary hyperhidrosis. Plast Reconstr Surg 1977;59:334-42.

4. Byrne J, Walsh TN, Herderman WP. Endoscopic transthoracic electrocautery of the sympathetic chain for palmar and axillary hyperdidrosis. Br J Surg 1990;77:1046-9.

5. Hurley HJ, ShelleyWB. Axillary hyperhidrosis. Br J Dermatol 1966;78:127-40.

6. Weaver PC. Axillary hyperhidrosis. Br Med J 1970;1:48.

7. Ellis H. Axillary hyperhidrosis: failure of subcutaneous curettage. Br Med J 1977;2:301-2.

8. Yoshikata R, Yanai A, Takei T, Shionome H. Surgical treatment of axillary osmidrosis. Br J Plast Surg 1990;43:483-5.

9. Ma S, Chiang SS, Fang RH. Prophylactic antibiotics in surgical treatment of axillary hyperhidrosis. Ann Plast Surg 1989;22:436-9.

10. Kuno Y. Human perspiration. Springfield: CC Thomas, 1956.

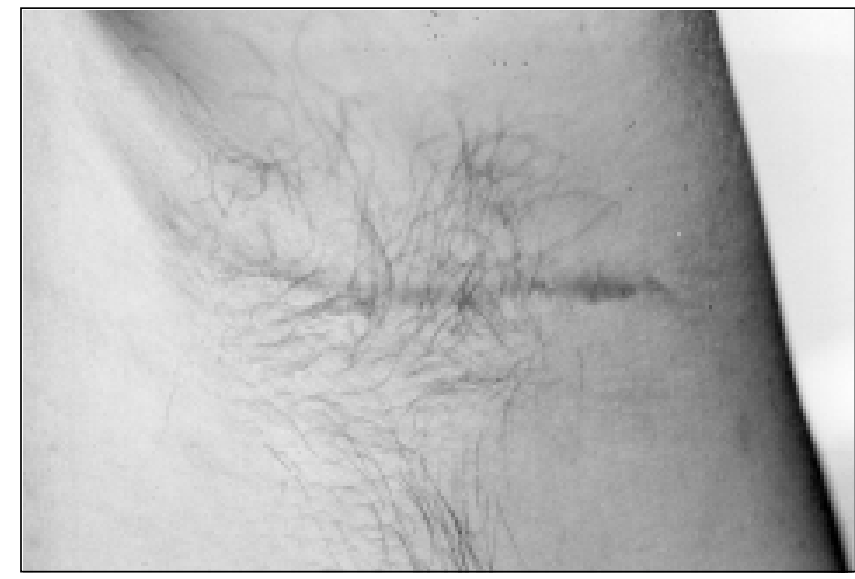

Figure 4) Typical scar three months after surgical treatment of axillary hyperhidrosis

Hurley and Shelly, and Weaver is outlined. The hair-bearing area of the axilla is excised, with undermining of vascular flaps, and simple closure. Radical excision of axillary sweat glands is achieved with no increase in complication rates when compared with other techniques. Scars in the axilla may become raised and spread initially but flatten and soften with time (Figure 4).

\section{CONCLUSION}

Although some patients with axillary hyperhidrosis can be treated conservatively, many require surgery for adequate resolution of their symptoms. Numerous surgical techniques have been developed yielding good results. The ideal surgical procedure would result in the removal of all of the responsible sweat glands while allowing for normal esthetics and function of the axilla. There are two broad categories for removal of the glandular material: those involving incision of the skin only and those where an ellipse of skin is excised with the glands. Radical excision of the hair-bearing area of the axilla is a relatively simple technique that can be used effectively to treat axillary hyperhidrosis. Patient satisfaction is high postoperatively with very little morbidity.

11. Rechardt L, Waris $\mathrm{T}$, Rintala A. Innervation of human axillary sweat glands. Histochemical and electron microscopic study of hyperhidrotic and normal subjects. Scand J Plast Reconstr Surg 1976;10:107-12.

12. Peters W. Treatment of axillary hyperhidrosis. Cutis 1982;29:366,368.

13. Johlin L, Evers H, Broberg F. Inhibition of hyperhidrosis by topical application of a local anestheticcomposition. Acta Derm Venereol (Stockholm) 1979;59:556-9.

14. Brandrup F, Larsen P. Axillary hyperhidrosis: local treatment with aluminium chloride hexahydrate $25 \%$ in absolute ethanol. Acta Derm Venereol (Stockholm) 1978;58:461-5.

15. Scholes KT, Crow KD, Ellis JP, Harman RR, Saihan EM. Axillary hyperhidrosis treated with alcoholic solution of aluminium chloride hexahydrate. Br Med J 1978;2:84-5.

16. Elgart ML, Fuchs G. Tapwater iontophoresis in the treatment of hyperhidrosis. Use of the Drionic device. Int J Dermatol 1987;26:194-7.

17. Midtgaard K. A new device for the treatment of hyperhidrosis by iontophoresis. Br J Dermatol 1986;114:485-8. 
18. Kobayashi T. Electrosurgery using insulated needles: treatment of axillary bromhidrosis and hyperhydrosis. J Dermatol Surg Oncol 1988;14:749-52.

19. Austin JJ, Doobay B, Schatz S. Transaxillary endoscopic laser sympathectomy. Can J Surg 1992;35:414-6.

20. Thuse MG. Axillary skin excision for axillary hyperhidrosis. Br J Clin Pract 1981;35:353-5.

21. Christ JE. The application of suction-assisted lipectomy for the problem of axillary hyperhidrosis. Surg Gynecol Obstet 1989;169:457.

22. Shenaq SM, Spira M, Christ J. Treatment of bilateral axillary hyperhidrosis by suction-assisted lipolysis technique. Ann Plast Surg 1987;19:548-51.

23. Ashby EC, Williams JL. Cryosurgery for axillary hyperhidrosis. Br Med J 1976;2:1173-4.
24. Skoog T, Thyresson N. Hyperhidroiss of the axilla: a method of surgical treatment. Acta Chir Scand 1962;124:531-8.

25. Jemec B, Holm Hansen B. Follow-up of patients operated on for axillary hyperhidrosis by subcutaneous curettage. Scand J Plast Reconstr Surg 1978;12:65-7.

26. Kappesser HJ. The use of a housed razor blade in the surgical management of axillary hyperhidrosis. J Dermatol Surg Oncol 1979;5:288-9.

27. Hurley HJ, Shelley WB. A simple surgical approach to the management of axillary hyperhidrosis. JAMA 1963;186:109-12.

28. Bretteville-Jensen G, Mossing N, Albrechtsen R. Surgical treatment of axillary hyperhidrosis in 123 patients. Acta Derm Venereol (Stockholm) 1975;55:73-7.

29. Eldh J, Fogdestam I. Surgical treatment of hyperhidrosis axillae. Scand J Plast Reconstr Surg 1976;10:227-9. 